\title{
Optimizing Well-Being: The Empirical Encounter of Two Traditions
}

\author{
Corey L. M. Keyes \\ Emory University
}

\author{
Dov Shmotkin \\ Tel-Aviv University
}

\author{
Carol D. Ryff \\ University of Wisconsin-Madison
}

\begin{abstract}
Subjective well-being (SWB) is evaluation of life in terms of satisfaction and balance between positive and negative affect; psychological well-being (PWB) entails perception of engagement with existential challenges of life. The authors hypothesized that these research streams are conceptually related but empirically distinct and that combinations of them relate differentially to sociodemographics and personality. Data are from a national sample of 3,032 Americans aged 25-74. Factor analyses confirmed the related-but-distinct status of SWB and PWB. The probability of optimal well-being (high SWB and PWB) increased as age, education, extraversion, and conscientiousness increased and as neuroticism decreased. Compared with adults with higher SWB than PWB, adults with higher PWB than SWB were younger, had more education, and showed more openness to experience.
\end{abstract}

Research on well-being has flourished in recent decades (Diener, Suh, Lucas, \& Smith, 1999; Kahneman, Diener, \& Schwarz, 1999), with increasing recognition of the different streams of inquiry guiding this broad domain. Ryan and Deci's (2001) integrative review organized the field of well-being into two broad traditions: one dealing with happiness (hedonic well-being), and one dealing with human potential (eudaimonic well-being; Ryan \& Deci, 2001; see also Waterman, 1993). In the present study, we draw and extend these distinctions, which we refer to as traditions of research on subjective well-being (SWB) and psychological well-being (PWB). We use these terms to underscore the fact that studies of SWB have repeatedly included not only affective indicators of happiness (hedonic well-being) but also cognitive assessments of life satisfaction. In addition, some aspects of PWB (e.g., personal growth, purpose in life) but not others (e.g., positive relations with others, self-acceptance) reflect the self-fulfillment meanings of eudaimonic well-being. As described below, SWB and PWB are also the overarching phrases most frequently used in

Corey L. M. Keyes, Department of Sociology and Department of Behavioral Sciences and Health Education, Rollins School of Public Health, Emory University; Dov Shmotkin, Department of Psychology, Tel-Aviv University, Tel-Aviv, Israel; Carol D. Ryff, Department of Psychology and Institute on Aging and Adult Life, University of WisconsinMadison.

This research was supported by the membership of Corey L. M. Keyes and Carol D. Ryff in the John D. and Catherine T. MacArthur Foundation Research Network on Successful Midlife Development. Portions of this article were initiated while Corey L. M. Keyes and Dov Shmotkin were Fellows of the Institute on Aging and Adult Life, University of Wisconsin-Madison.

Correspondence concerning this article should be addressed to Corey L. M. Keyes, Department of Sociology, Emory University, Tarbutton Hall, Atlanta, Georgia 30322. E-mail: ckeyes@emory.edu studies that constitute these traditions, both of which are fundamentally concerned with subjective accounts of well-being.

Our specific empirical aims are to examine whether indicators of SWB and PWB constitute taxonomically distinct reflections of well-being in a national sample of U.S. adults. Although both approaches assess well-being, they address different features of what it means to be well: SWB involves more global evaluations of affect and life quality, whereas PWB examines perceived thriving vis-à-vis the existential challenges of life (e.g., pursuing meaningful goals, growing and developing as a person, establishing quality ties to others). We further test the hypothesis that these distinct varieties of well-being are contoured by the broad categories of sociodemographic and personality factors. Specifically, we investigate the role of location in the life course (i.e., age) and position in the socioeconomic hierarchy (e.g., educational status) as well as personality traits in accounting for different profiles of well-being. To put the inquiry in historical context, we provide a brief summary of each tradition.

\section{Traditions in Well-Being Research}

\section{$S W B$}

SWB emerged in the late 1950s in the search for useful indicators of quality of life to monitor social change and improve social policy (Land, 1975). As milestones in this literature, books by Andrews and Withey (1976) and Campbell, Converse, and Rodgers (1976) clarified that although people live in objectively defined environments, it is their subjectively defined worlds that they respond to, thus giving prominence to SWB as a relevant index of people's life quality. Other influential volumes at the time (Bradburn, 1969; Cantril, 1965; Gurin, Veroff, \& Feld, 1960) emphasized life satisfaction and happiness as components of life quality.

Life satisfaction, according to Campbell et al. (1976), reflects individuals' perceived distance from their aspirations. Happiness, 
in turn, according to Bradburn (1969), results from a balance between positive affect and negative affect. These founding contributions underscored different temporal frames of SWB: satisfaction is a judgmental, long-term assessment of one's life, whereas happiness is a reflection of pleasant and unpleasant affects in one's immediate experience. The threefold structure of life satisfaction, positive affect, and negative affect has been repeatedly confirmed in numerous studies (Lucas, Diener, \& Suh, 1996). The alleged independence of positive and negative affect has received particular scrutiny. Although certain measurement artifacts affect the correlation between the two affects (Green, Goldman, \& Salovey, 1993; Russell \& Carroll, 1999), considerable evidence confirms the functional separation of positive and negative affect within SWB as well as in the configuration of emotions at large (Cacioppo, Gardner, \& Berntson, 1999; Diener, Smith, \& Fujita, 1995; Keyes, 2000).

Social gerontology also advanced SWB-related concepts as outcomes in studies of the aging process (Okun, 1995). Initial research revealed that aging was not as uniformly associated with declines of SWB as many had expected. Positive affect shows evidence of both decline and gain with age, negative affect seems to remain stable for some and to decline for others, ${ }^{1}$ and life satisfaction may even increase (Charles, Reynolds, \& Gatz, 2001; Diener \& Suh, 1997; Mroczek \& Kolarz, 1998; Shmotkin, 1990). These findings shed light on possible modes of adaptation to growing old (Shmotkin, 1998). The gerontological studies of SWB also generated widely used measures of SWB (Lawton, 1975; Neugarten, Havighurst, \& Tobin, 1961), analyses of which confirmed that SWB serves as a high-order factor but relies on lower order themes such as the need of the elderly to reconcile themselves to the adversities of older adulthood (e.g., Liang, 1984; Shmotkin \& Hadari, 1996).

The study of SWB currently permeates a variety of social and health disciplines interested in quality of life (Raphael, Renwick, Brown, \& Rootman, 1996). In addition, there is increasing interest in SWB within major areas of mainstream psychology (Diener et al., 1999). Thus, SWB is being studied as a cognitive process of judgment and attribution (Schwarz \& Clore, 1983; Tversky \& Griffin, 1991), constituents of emotional experience (Diener, Sandvik, \& Pavot, 1991; Lazarus, 1991), goal-related behavior (Emmons, 1996; Omodei \& Wearing, 1990; Sheldon \& Elliot, 1999), time perspective (Shmotkin, 1991; Strack, Schwarz, \& Gschneidinger, 1985), short-term and long-term effects of life events (Shmotkin \& Lomranz, 1998), and cross-cultural variability (Suh, Diener, Oishi, \& Triandis, 1998).

The determinants of SWB have been linked to heredity (Lykken \& Tellegen, 1996), personality (McCrae \& Costa, 1994), mutable living conditions (Veenhoven, 1991), and currently accessible information (Schwarz \& Strack, 1999). The possible combinations of such determinants have engendered interest in top-down versus bottom-up causal formulations (e.g., Feist, Bodner, Jacobs, Miles, $\&$ Tan, 1995) and related questions about the dynamic processes involved in the long- and short-term variability of SWB. These include the notion of adaptation that weakens external influences and restores the individual's normal baseline of SWB (Headey \& Wearing, 1989), comparison mechanisms that regulate SWB on the basis of perceived gaps between one's own experience and self-standards (Michalos, 1985), and goal systems that prioritize personal aims according to core motivations and values of the self (Emmons, 1996).

\section{$P W B$}

Whereas the SWB tradition formulates well-being in terms of overall life satisfaction and happiness, the PWB tradition draws heavily on formulations of human development and existential challenges of life. An extensive literature generated in the 1950s and 1960s addressed variations in optimal resolution of basic life challenges (see Ryff, 1985, for reviews). Early life-span theorists such as Erik Erikson (1959) and Bernice Neugarten (1973) articulated age-graded tasks and the ways they are successfully negotiated. Psychologists interested in the full growth and development of the individual have articulated constructs such as selfactualization (Abraham Maslow, 1968), full functioning (Carl Rodgers, 1961), maturity (Gordon Allport, 1961), and individuation (Carl Jung, 1933). Jahoda's (1958) criteria of positive mental health draw on many of these conceptualizations to offer a description of what it means to be psychologically healthy.

These prior conceptions of positive functioning had little impact on empirical studies of well-being, largely because of the absence of valid and reliable assessment procedures. Looking for the key points of convergence among the many formulations, Ryff (1989a) suggested a multidimensional model of PWB that distilled six psychological dimensions of challenged thriving. Each dimension of PWB articulates different challenges individuals encounter as they strive to function positively (Ryff, 1989a; Ryff \& Keyes, 1995). That is, people attempt to feel good about themselves even while aware of their own limitations (self-acceptance). They also seek to develop and maintain warm and trusting interpersonal relationships (positive relations with others) and to shape their environment so as to meet personal needs and desires (environmental mastery). In sustaining individuality within a larger social context, people also seek a sense self-determination and personal authority (autonomy). A vital endeavor is to find meaning in one's efforts and challenges (purpose in life). Lastly, making the most of one's talents and capacities (personal growth) is central to PWB.

Studies have documented sociodemographic variability (by age, gender, and education) in the dimensions of PWB (Clarke, Marshall, Ryff, \& Rosenthal, 2000; Keyes \& Ryff, 1998; Marmot, Ryff, Bumpass, Shipley, \& Marks, 1997; Ryff \& Keyes, 1995; Ryff \& Singer, 1996) and have linked PWB with life transitions and experiences such as parenthood (Ryff, Schmutte, \& Lee, 1996), community relocation (Kling, Ryff, \& Essex, 1997; Kling, Seltzer, \& Ryff, 1997; Smider, Essex, \& Ryff, 1996), and health changes of later life (Heidrich \& Ryff, 1993). Across these studies, emphasis has been given to intervening psychosocial processes such as social comparisons, reflected appraisals, coping strategies, and psychological centrality. The capacity to maintain high levels of purpose, mastery, or growth in the face of cumulative adversity has also led to a focus on resilience (Ryff, Singer, Love, \& Essex,

\footnotetext{
${ }^{1}$ Mroczek and Kolarz (1998) found that, after they controlled for a host of variables (i.e., sociodemographic, personality and health variables), negative affect was unrelated with age among women and decreased with age among married men.
} 
1998; Singer, Ryff, Carr, \& Magee, 1998). The well-being scales have also been extensively used by other investigators, both within psychology and beyond, to study well-being outcomes in response to various life challenges, such as personal projects (McGregor \& Little, 1998), body consciousness (McKinley, 1999), work aspirations and achievements (Carr, 1997), marital status change (Marks \& Lambert, 1998), caregiving (Li, Seltzer, \& Greenberg, 1997), and recovery from depression (Fava, Rafanelli, Grandi, Conti, \& Belluardo, 1998).

\section{Toward an Integrative Taxonomy of Well-Being}

\section{Emergent Evidence of "Related But Distinct"}

Although the well-being traditions have evolved separately, increasing evidence draws connections between the two. An emergent theme therein is that SWB and PWB are related but distinct aspects of positive psychological functioning. For example, factor analysis of a variety of well-being measures (Compton, Smith, Cornish, \& Qualls, 1996) has delineated two correlated factors of SWB (e.g., happiness, life satisfaction) and Personal Growth (e.g., openness to experience, maturity). A more recent study by McGregor and Little (1998) yielded two distinct factors of Happiness (including depression, positive affect, and life satisfaction) versus Meaning (including four of Ryff's, 1989a, PWB scales: Personal Growth, Purpose in Life, Positive Relations With Others, and Autonomy). This distinction was validated through factor analysis and the differential association of Happiness with goal efficacy, on the one hand, and of Meaning with goal integrity, on the other. Previously, Ryff and Keyes (1995) used data from multiple studies to investigate associations between PWB and SWB: Moderate associations were found between two PWB scales (Self-Acceptance and Environmental Mastery) and measures of happiness and life satisfaction, although the remaining four dimensions of PWB (autonomy, personal growth, positive relations with others, purpose in life) showed mixed or weak relationships to SWB.

Distinctions between a happy life and a meaningful life have emerged in studies using less conventional measures of SWB and PWB. King and Napa (1998) found that respondents perceived happiness and meaning as determinants of the desirability of the good life. Similarly, a qualitative study among middle-aged and older aged adults revealed the importance of enjoyment and challenges in lay conceptions of well-being (Ryff, 1989b). Waterman (1993) found strong positive correlations between reports of hedonic enjoyment and reports of personal expressiveness in important activities. However, personal expression was associated more strongly than was hedonic enjoyment with feeling challenged and with fulfilling one's potential.

Collectively, these studies and the literatures preceding them suggest a dual approach to characterizations of well-being. Extending this perspective, we propose a typological model based on cross-classification of levels of SWB and PWB. The ondiagonal types represent those individuals with consistent levels, either low or high, in both modes of well-being. However, the model also depicts off-diagonal types that present disparate levels, where SWB is high and PWB is low or vice versa. Although SWB and PWB may complement each other in the on-diagonal types, they may compensate for each other in the off-diagonal types.
This typology necessitates empirical confirmation that SWB and PWB maintain a relation of interdependence that allows for viable combinations of both. We conducted such an analysis with a national sample of Americans to maximize the likelihood of capturing the full range of diversity suggested by the model. Our hypothesis is that the best fitting factorial model is one of two correlated latent factors rather than a model consisting of two uncorrelated factors or one factor only. Beyond testing this dimensional structure, we further propose that the combinations of levels of PWB and SWB are contoured by the factors discussed next.

\section{The Contouring of Well-Being}

We hypothesize that the varieties of well-being are meaningfully structured by sociodemographic variables, notably age and educational level, and by enduring personality characteristics. Prior literatures have connected these kinds of influences to wellbeing, but for SWB or PWB separately. Our emphasis is on the role of sociodemographic and personality variables to illuminate various ways SWB and PWB come together.

Age and educational status. Chronological age and educational attainment define an individual's position in the social structure. Conceptually, interest in age variation in well-being is tied to psychological formulations of life course development (Neugarten, 1973; Ryff, 1989a), which underscore the centrality of particular life challenges in the move from young adulthood through midlife into old age. In turn, sociological accounts of the life course suggest that institutional opportunities for meaningful activity lag behind the added years that many older persons now experience (Riley, Kahn, \& Foner, 1994). Beyond age-related influences on well-being, we also emphasize educational standing, thereby connecting our inquiry to the growing interest in social inequalities - that is, how differential access to resources and opportunities in life influences health and well-being (Adler, McEwen, \& Marmot, 1999; Marmot et al., 1997; Witter, Okun, Stock, \& Haring, 1984). This multidisciplinary literature increasingly draws on psychological constructs to articulate the mechanisms and processes through which standing in the socioeconomic hierarchy penetrates self-evaluation and life quality (see Ryff \& Marshall, 1999).

We hypothesized that individuals who possess high profiles of both SWB and PWB would be individuals with educational advantage and who were in middle adulthood, the latter representing peak years of norm bearing, decision making, and influence in work and family life (Neugarten, 1968). Alternatively, we expected those with low profiles on both forms of well-being to be individuals who lacked educational advantage and were younger in age, the combined effects of which underscore troubling constraints on life opportunity at a time when adult roles and identities are being forged. Regarding the off-diagonal types (high PWB/low SWB, low PWB/high SWB), the prediction was that early adulthood (representing the energy and promise of youth), when combined with educational advantage, is especially conducive to challenged thriving (i.e., high PWB). The demands of such striving may, however, compromise contentment or more hedonic aspects of well-being. Alternatively, later life was hypothesized to evoke greater constraints (biological and social structural) on challenged thriving, especially in the absence of educational advantage. Hav- 
ing weathered the challenges of earlier decades, older, lesseducated individuals may be content and satisfied (high SWB) but, because of lack of capacity or opportunity, may have lower levels of PWB.

Personality traits. A large body of evidence has shown personality to be a potent predictor of SWB (see reviews by DeNeve \& Cooper, 1998; Diener \& Lucas, 1999; Diener et al., 1999). Costa and McCrae (1980) demonstrated the differential links between extraversion and positive affect and between neuroticism and negative affect, a finding confirmed in later studies (e.g., Emmons \& Diener, 1985; Headey \& Wearing, 1989; Watson \& Clark, 1992) and purportedly explained by an array of genetic, biological, psychological, and social mechanisms (Diener et al., 1999). Beyond these two dimensions, other personality dimensions, namely Conscientiousness and Agreeableness, may influence SWB instrumentally by engendering conditions, behaviors, and life events that facilitate or moderate SWB. Of the Big Five personality dimensions, Openness to Experience has shown the weakest associations with SWB, possibly because it may evoke both positive and negative affects (DeNeve \& Cooper, 1998; McCrae \& Costa, 1991). Integrative reviews of the literature indicate that personality, despite its impact, can explain only a limited variance relating to the vicissitudes of SWB and its reactivity to mental processes and life experiences (DeNeve \& Cooper, 1998; Diener \& Lucas, 1999).

Personality has been strongly linked with PWB dimensions. Controlling for problems related to construct overlap (blurred item content) and source overlap (using the same respondents to assess both personality and well-being), Schmutte and Ryff (1997) found that Neuroticism, Extraversion, and Conscientiousness emerged as strong and consistent predictors of multiple aspects of well-being (particularly self-acceptance, environmental mastery, and purpose in life). However, other aspects of PWB revealed distinctive personality correlates. Openness to Experience, for example, emerged as strongly predictive (along with Extraversion) of the personal growth dimension of well-being, whereas Agreeableness predicted positive relations with others. Autonomy, the final dimension of PWB, was predicted by multiple traits, but most strongly by Neuroticism.

Drawing on the well-being typology, we seek to relate personality traits not to SWB and PWB as separate domains but to their combinations. We hypothesize that Extraversion, Neuroticism, and Conscientiousness strongly differentiate between the on-diagonal types of well-being (in which SWB and PWB coincide at either high or low levels). Regarding the off-diagonal types, we predict that Openness to Experience will predict those who possess high PWB but low SWB, whereas Agreeableness will predict the high SWB but low PWB combination. The on-diagonal hypothesis is well grounded in prior evidence that has linked Neuroticism, Extraversion, and sometimes Conscientiousness to both varieties of well-being. The first off-diagonal hypothesis integrates separate findings noted above-namely, that Openness to Experience strongly predicts the most explicitly eudaimonic aspect of wellbeing (personal growth) but is not clearly predictive of hedonic well-being. Conversely, we speculate that the off-diagonal type of high life contentment combined with limited self-fulfillment may be particularly facilitated by an agreeable, accommodative disposition.

\section{Method}

\section{Sample and Procedure}

Data are from the Midlife in the U.S. (MIDUS) survey conducted by the John D. and Catherine T. MacArthur Foundation's Research Network on Successful Midlife Development. MIDUS is a national probability sample, drawn with random-digit dialing procedures, that consists of Englishspeaking, noninstitutionalized adults aged 25 to 74 years who reside in the 48 contiguous states and whose household includes at least one telephone. The first stage of the multistage sampling design selected households with equal probability through telephone numbers. Disproportionate stratified sampling was used at the second stage to select respondents. The sample was stratified by age and sex, with oversampling of men between the ages of 65 and 74 . Working but nonhousehold telephone numbers (e.g., businesses) were eliminated by definition. Working telephone numbers that were unsuccessfully contacted 10 times were also eliminated.

Adults who agreed to participate were administered a computer-assisted telephone interview lasting $45 \mathrm{~min}$ on average and were then mailed two questionnaire booklets requiring about $1.5 \mathrm{hr}$ on average to complete. All participants were offered $\$ 20$ and a copy of a final study monograph as incentives for participation. With a response rate of $70 \%$ for the telephone phase and a response rate of $87 \%$ for the self-administered questionnaire phase, the overall response rate was $61 \%$, with a sample size of 3,032 respondents. Field procedures lasted approximately 13 months in 1994-1995.

Table 1 reports the demographic characteristics of the sample when unweighted and when weighted. The sample weight adjusts for unequal probabilities of household selection and unequal probabilities of respondent selection within households. Moreover, the sample weight poststrati-

Table 1

Sample Characteristics of the MIDUS Sample $(N=3,032)$

\begin{tabular}{llcc}
\hline $\begin{array}{l}\text { Demographic } \\
\text { variable }\end{array}$ & \multicolumn{1}{c}{ Breakdown } & $\begin{array}{c}\text { Unweighted } \\
\%\end{array}$ & $\begin{array}{c}\text { Weighted } \\
\%\end{array}$ \\
\hline Age & & & \\
& Young adults, 25-39 & 33.2 & 40.5 \\
& Midlife adults, 40-59 & 46.0 & 40.3 \\
Gender & Older adults, 60-74 & 20.8 & 19.2 \\
& & & \\
\multirow{3}{*}{ Education } & Men & 48.5 & 43.5 \\
& Women & 51.5 & 56.5 \\
Marital status & 12 years or fewer & 39.2 & 51.5 \\
& 13 years or more & 60.8 & 48.5 \\
Race & Married & 64.1 & \\
& All others & 35.9 & 68.1 \\
& Caucasian & 87.8 & \\
& African American & 6.8 & 11.4 \\
& All other races & 4.4 & 5.7 \\
\hline
\end{tabular}

Note. Sample weight consists of a poststratification component to match the sociodemographic distribution of the United States on the basis of the October 1995 Current Population Survey. The mean age of the unweighted sample was $47.0(S D=13.1)$; when the sample is weighted, $M=45.3(S D=13.5)$. MIDUS $=$ Midlife in the United States survey conducted in 1995 by the John D. and Catherine T. MacArthur Foundation's Research Network on Successful Midlife Development. 
fies the sample to match the October 1995 Current Population Survey ${ }^{2}$ proportions of adults on the basis of age, gender, education, marital status, and race as well as the proportions of adults residing in metropolitan and nonmetropolitan areas and the regions (northeast, midwest, south, and west) of the United States. Analyses were run on both the weighted and the unweighted data.

\section{Measures}

$S W B$. Measures included a single-item measure of global life satisfaction and scales of positive and negative affect. The life satisfaction measure was an adaptation of Cantril's (1965) Self-Anchoring Scale, and it asked respondents to "rate their life overall these days" on a scale from 0 to 10 , where $0=$ worst possible life overall and $10=$ the best possible life overall. Variants of Cantril's measure have been used extensively in numerous studies worldwide, usually providing satisfactory psychometric properties (Andrews \& Robinson, 1991). The affect measure asked respondents to indicate how much of the time during the past 30 days they felt six types of negative and six types of positive indicators of affect, on a scale ranging from none of the time (1) to all of the time (5). The negative terms were (a) "so sad nothing could cheer you up," (b) "nervous," (c) "restless or fidgety," (d) "hopeless," (e) "that everything was an effort," and (f) "worthless." The positive terms were (a) "cheerful," (b) "in good spirits," (c) "extremely happy," (d) "calm and peaceful," (e) "satisfied," and (f) "full of life." The negative affect scale items were reverse coded so that higher scores represent the experience of less negative affect; the positive affect scale items were coded so that higher scores indicate the experience of more positive affect. Summed scores were created for each affect scale. The internal (alpha) reliability of the negative affect scale was .87 , and for the positive affect scale the reliability was .91 . For a description of the development of affect measures, see Mroczek and Kolarz (1998).

$P W B$. Measures included Ryff's (1989a) six scales of PWB: SelfAcceptance, Environmental Mastery, Positive Relations With Others, Personal Growth, Purpose in Life, and Autonomy. Each scale consisted of three items, with a mix of positive and negative items. On a scale from 1 to 6 , respondents indicated whether they agreed or disagreed strongly, moderately, or slightly that an item described how they thought and felt. Negative items were reverse coded so that higher scores on each scale reflect the presence of more positive appraisals. Summed scores were created from all multiple-item scales.

These short-form scales had previously confirmed the proposed theoretical structure of PWB and replicated age and gender differences in a separate, nationally representative sample (see Ryff \& Keyes, 1995). Consistent with this prior investigation, the reduced-item scales in this study exhibited lower to modest internal (alpha) reliabilities (see Table 2). The lower reliability stemmed from the decision to reduce the number of items for administration over the telephone and to choose items that maximized content validity rather than internal consistency (see Ryff \& Keyes, 1995). ${ }^{3}$ Such low reliabilities could limit the degree to which PWB scales correlate with other variables, but, as our findings show, this has not occurred.

Personality. Measures of the five-factor personality dimensions (Lachman \& Weaver, 1997) were assessed by 25 self-descriptive adjectives selected from previous inventories of the Big Five (e.g., John, 1990). The scale construction was conducted in 1994 with a U.S. probability sample of 1,000 respondents aged 30 to 70 years. Participants rated the degree to which each item described them on a scale ranging from a lot (1) to not at all (4). Scores were the mean ratings for each dimension. Ratings were reverse coded when necessary, so that higher scores reflect higher standing on each dimension. Alpha internal consistency coefficients obtained in the MIDUS database were .78 for Extraversion (outgoing, friendly, lively, active, talkative), .74 for Neuroticism (moody, worrying, nervous, calm [reverse scored]), .58 for Conscientiousness (organized, responsible, hardworking, careless [reverse scored]), .80 for Agreeableness (helpful, warm, caring, softhearted, sympathetic), and .77 for Openness to Experience (creative, imaginative, intelligent, curious, broadminded, sophisticated, adventurous). For more details on the Big Five scales in MIDUS, see Prenda and Lachman (2001).

\section{Results}

\section{The Joint Structure of SWB and PWB}

Table 2 presents the bivariate correlations and descriptive statistics of the indicators of well-being. All correlations $(p<.001)$ were positive and ranged from small (lowest $=.13$ ) to modest (largest $=.62$ ). The measures of SWB intercorrelated modestly. Thus, adults who perceived their lives as better were more likely to report the presence of positive affect and the absence of negative affect. Also, the presence of positive affect correlated with the absence of negative affect $(r=.62)$. All PWB scales correlated positively. The scales of PWB also correlated positively with all scales of SWB. Moreover, the bivariate correlation between the summed scale of SWB and the summed scale of PWB was .59 $(p<.001)$. Thus, adults who tended to report higher levels of PWB (e.g., more personal growth) also tended to report feeling more positive affect and less negative affect and to evaluate their life satisfaction more positively.

Although the bivariate correlations suggest some shared variance among the measures, the first hypothesis is that well-being is composed of related but distinct facets. We used exploratory and then confirmatory factor analysis (using LISREL 8; Jöreskog \& Sörbom, 1996) to explicitly test theoretical models of the latent structure of well-being. The exploratory analysis is based on a random subsample of approximately half of the original sample. Using oblique rotation of principal-components extraction, we found that both the scree plot and the eigenvalue-greater-than-one criteria indicated a two-factor structure. As the findings in Table 3 suggest, the measures of SWB and PWB constitute distinctive factors with partially overlapping indicators. The results based on the weighted sample, as currently reported, were similar to those based on the unweighted sample. Although none of the measures of SWB overlapped with the PWB factor, three (i.e., SelfAcceptance, Environmental Mastery, and Positive Relations With Others) of the six scales of PWB loaded on both factors. The estimated correlation between the factors is .45 .

Using the remaining random subsample for replication, we then conducted confirmatory factor analysis to test the fit of the data to competing theoretical models. Table 4 presents the estimates of six alternative models. The results based on the weighted sample, as currently reported, were similar to those based on the unweighted sample. We began with a baseline model in which there were as

\footnotetext{
${ }^{2}$ This survey is conducted jointly by the U. S. Bureau of Labor Statistics and the Census Bureau. For more information about this survey, see http://www.bls.census.gov/cps/cpsmain.htm

${ }^{3}$ The original 20-item scales of each dimension consisted of two and sometimes three subfactors, reflecting the diverse strands of underlying theory that composed the definitions for each scale of well-being. The 3 items for the short-form assessments were chosen to represent these subfactors. That is, an a priori decision was made to select items that represented the theoretical scope of each well-being construct. This diversity in item content reduces the internal consistency coefficients for the 3-item scales but keeps them meaningfully connected to the theoretical starting points for the parent scales.
} 
Table 2

Correlations and Descriptive Statistics of the Well-Being Indicators (Sample Weighted)

\begin{tabular}{lccccccccc}
\hline \multicolumn{1}{c}{ Indicator } & 1 & 2 & 3 & 4 & 5 & 6 & 7 & 8 & 9 \\
\hline 1. Life satisfaction & - & .52 & .46 & .48 & .32 & .25 & .21 & .45 & .16 \\
2. Positive affect & & $(.91)$ & .62 & .50 & .38 & .28 & .19 & .50 & .19 \\
3. Negative affect & & & $(.87)$ & .50 & .39 & .28 & .27 & .49 & .21 \\
4. Self-acceptance & & & & $(.59)$ & .48 & .41 & .35 & .58 & .27 \\
5. Positive relations & & & & & $(.58)$ & .40 & .39 & .36 & .20 \\
6. Personal growth & & & & & & $(.55)$ & .39 & .38 & .21 \\
7. Purpose in life & & & & & & & $(.37)$ & .25 & .13 \\
8. Environmental mastery & & & & & & & & $(.52)$ & .29 \\
9. Autonomy & 7.7 & 20.2 & 26.4 & 16.4 & 16.0 & 17.8 & 16.2 & 15.9 & 16.4 \\
$M$ & 1.7 & 4.5 & 3.9 & 3.5 & 4.1 & 3.2 & 3.7 & 3.4 & 3.4 \\
$S D$ & & & & & & & & &
\end{tabular}

Note. Internal alpha reliability estimates are in parentheses (life satisfaction is a single item). For all correlations, $p<.001$ (two-tailed).

${ }^{a}$ The negative affect scale is reverse coded so that a higher score means less negative affect.

many latent constructs as measures of well-being, which suggests that the observed measures of well-being were independent. The chi-square statistic was very large for the independence model, indicating that the theory that the latent construct of well-being consists of innumerable independent dimensions is untenable. However, the single-factor model provided a vastly improved fit to the data, suggesting that a more tenable model assumes that the measures of well-being reflect a common source of variance.

Next, we fit Model 3-which hypothesized that SWB and PWB are two uncorrelated factors- to the data. Relative to the singlefactor model, the two-orthogonal-factor model had a very poor fit to the data. Thus, either the measures reflect a common source or they reflect two distinct latent constructs that are correlated.

Table 3

Factor Analysis of Measures of SWB and PWB Based on a Random Subsample of the Total Sample ( $n=1,514$; Sample Weighted)

\begin{tabular}{lrr}
\hline & \multicolumn{2}{c}{$\begin{array}{c}\text { Factor structure } \\
\text { coefficients }\end{array}$} \\
\cline { 2 - 3 } \multicolumn{1}{c}{ Measure } & SWB & PWB \\
\hline Life satisfaction & $\mathbf{. 7 4}$ & .29 \\
Positive affect & $\mathbf{. 8 3}$ & .30 \\
Negative affect & $\mathbf{. 8 0}$ & .36 \\
Self-acceptance & $\mathbf{. 7 4}$ & $\mathbf{. 6 1}$ \\
Environmental mastery & $\mathbf{. 7 5}$ & $\mathbf{. 4 7}$ \\
Positive relations & $\mathbf{. 5 0}$ & $\mathbf{. 7 0}$ \\
Personal growth & .36 &. $\mathbf{7 6}$ \\
Purpose in life & .24 & .79 \\
Autonomy & .33 & .36 \\
Eigenvalue & 3.9 & 1.1 \\
\% variance & 43.7 & 12.3 \\
Cumulative variance explained & 43.7 & 56.0 \\
\hline
\end{tabular}

Note. Presented is the structure matrix of a principal-components extraction with direct oblimin rotation. The correlation between factors is .45 . Loadings above .40 appear in boldface. SWB = subjective well-being; $\mathrm{PWB}=$ psychological well-being.

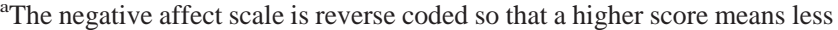
negative affect.
Model 4 therefore allowed the latent SWB and PWB constructs to correlate. It provided a superior fit to the data relative to Model 2. The chi-square contrast revealed that the two-correlated-factor model was superior to the single-factor model $(362-212=150$, with $27-26=1 d f \mathrm{~s}, p<.001)$. Moreover, the indices of fit of Model 4 all suggested that it was an excellently fitting model (e.g., adjusted goodness-of-fit index $=.94$, comparative fit index $=.95$ ) and therefore a good theory of the latent structure of the measures of SWB and PWB.

Notwithstanding support for our first hypothesis, the exploratory factor analysis suggested an even better fitting model in which the measures of self-acceptance and environmental mastery were either caused solely by SWB or caused by both SWB and PWB. Thus, Model 5 presents the fit of the two-oblique-factor model in which self-acceptance and environmental mastery were caused only by SWB. Model 6, however, presents the fit of the twooblique-factor model in which self-acceptance and environmental mastery were caused by both SWB and PWB. Model 6 provided a much better fit to the data than did Model 4. The chi-square contrast of Model 6 relative to Model 4 was $212-137=75$, with $26-24=2 d f_{\mathrm{S}}(p<.001)$. Although self-acceptance and environmental mastery were caused by both latent factors, the hypothesis that measures of SWB and PWB emanate from distinctive kinds of well-being is strongly supported.

Figure 1 presents the standardized loadings for Model 4 (theoretical model), and Figure 2 presents the standardized loadings for Model 6 (modified theoretical model). Although Model 6 provided a better fit to the data than did Model 4, both may serve as a basis for further inquiries. In addressing our typological analysis, we considered Model 4 more useful than Model 6 for several reasons. First, Model 4 maintains the conceptual differentiation between the two traditions of SWB and PWB. Second, the high loadings of self-acceptance and environmental mastery on PWB in Model 4 (.80 and .71, respectively) are drastically attenuated when these dimensions load on both SWB and PWB in Model 6 (.35 and .49, respectively, for self-acceptance; .47 and .28 for environmental mastery). With the exception of the relatively low loading of autonomy (.37) in Model 4, this diffusion in Model 6 sets far lower loadings than desirable for the well-being indicators. Third, the 
Table 4

Fit Indices of Confirmatory Factor Analyses (Maximum Likelihood Estimation) of Measures of SWB and PWB Based on a Random Subsample of the Total Sample ( $n=1,444$; Sample Weighted)

\begin{tabular}{|c|c|c|c|c|c|c|c|c|}
\hline Model & $\chi^{2}(1444)$ & $d f$ & $p$ & AGFI & RMSEA & IFI & CFI & $\mathrm{CN}$ \\
\hline 1. Independence & $4,162.84$ & 36 & .00 & .32 & .38 & .00 & .00 & 21.3 \\
\hline 2. One factor & 362.17 & 27 & .00 & .90 & .10 & .92 & .92 & 188.1 \\
\hline 3. Two orthogonal factors & $1,080.48$ & 27 & .00 & .81 & .14 & .75 & .74 & 63.7 \\
\hline 4. Two oblique factors & 212.41 & 26 & .00 & .94 & .07 & .95 & .95 & 311.1 \\
\hline $\begin{array}{l}\text { 5. Two oblique factors with SA } \\
\text { and EM loading on SWB }\end{array}$ & 249.51 & 26 & .00 & .93 & .08 & .95 & .95 & 265.0 \\
\hline and PWB & 137.40 & 24 & .00 & .96 & .06 & .97 & .97 & 452.4 \\
\hline
\end{tabular}

Note. $\quad$ SWB $=$ subjective well-being; $\mathrm{PWB}=$ psychological well-being; $\mathrm{AGFI}=$ adjusted goodness-of-fit index; RMSEA $=$ root-mean-square error of approximation; $\mathrm{IFI}=$ incremental fit index; $\mathrm{CFI}=$ comparative fit index $; \mathrm{CN}=\operatorname{critical} N ; \mathrm{SA}=$ Self-Acceptance Scale; $\mathrm{EM}=$ Environmental Mastery Scale.

crosstabulation proposed for SWB and PWB would be partly obscured if an identical variance (i.e., self-acceptance and environmental mastery) was simultaneously introduced to both crosstabulated variables beyond their natural intercorrelation $(.84$ between the latent constructs in Model 4). In sum, although Model 6 demonstrates the partial overlapping and, hence, the high common variance between SWB and PWB conceptions, Model 4 more clearly presents them as correlated yet distinct in content.

\section{The Contouring of SWB and PWB by Sociodemographic Factors}

We hypothesized that various combinations of SWB and PWB are contoured by sociodemographic factors such as age and education. To investigate this hypothesis, we first summed the measures of SWB (alpha coefficient of overall scale $=.91$ ) and PWB (alpha coefficient of overall scale $=.81)^{4}$ and then examined their links to age and education.

On the basis of the weighted sample data, bivariate analysis revealed small correlations of SWB with age $(r=.13, p<.001)$ and with education $(r=.07, p<.001)$. Bivariate analyses also revealed a small correlation of PWB with education $(r=.20, p<$ $.001)$ but not with age. Multivariate analysis of variance of SWB and PWB by age (coded 25-39, 40-59, and 60-74 years) and education (12 or fewer years and 13 or more years), with gender, race, and marital status as covariates, revealed a similar pattern. There were mean differences in SWB by age, $F(2,2899)=33.6$, $p<.001$, but not by education, $F(1,2899)=0.2$. We also found a mean difference in PWB by education, $F(1,2899)=65.3, p<$ .001 , but not by age, $F(2,2899)=0.9$. The effect sizes of age for SWB were small, with eta-squared values of no greater than .01 ; the effect size of education for PWB was an eta-squared value of .02. Interaction effects were not significant.

Beyond these separate effects, the cross-classification of SWB and PWB by age and education was of particular interest. Toward that end, we computed the tertiles for SWB and PWB scales, coding each scale into low (first tertile), middle (second tertile), and upper (third tertile) levels. Using multinomial logistic regression, we then regressed the cross-classification of the trichotomies of SWB by PWB onto the age and education variables while controlling for race, gender, and marital status. We coded education and age into dummy variables to permit modeling of possible nonlinear relationships. Preliminary modeling revealed that the interactions of the Education $\times$ Age dummy variables did not provide a statistically significant improvement in fit of the model to the data. A final model, omitting the interaction variables, was estimated. Table 5 contains the coefficients and log odds of membership in a particular well-being cell by education and by age (controlled for race, gender, and marital status) when compared against membership in the reference cell (i.e., lower tertile of both SWB and PWB). The results based on the weighted sample, as currently reported, were similar to those based on the unweighted sample. For exposition, we focus on the outer cells with extreme combinations that reflect distinctive ways of being well (i.e., low SWB and high PWB; high SWB and low PWB; high SWB and high PWB).

First, compared with adults who have low SWB and low PWB (i.e., the reference cell), the odds of having the combination of high SWB with high PWB increased as education increased and as age increased. It is interesting to note that the odds of having the combination of low SWB with high PWB, compared with the reference cell, increased as education increased but were unrelated with age. In contrast, the odds of having high SWB with low PWB, compared with the reference cell, increased as age increased. Moreover, adults with 17 or more years of education were less likely than were adults with 11 or fewer years of education to have the combination of high SWB and low PWB, compared with the reference cell of low SWB and low PWB.

Put simply, adults with low SWB and high PWB tended to be more educated than adults with the combination of low SWB and low PWB. In contrast, adults with high SWB and low PWB tended to be slightly less educated and older than adults with the combination of low SWB and low PWB. Adults with high SWB and high

\footnotetext{
${ }^{4}$ Because the measures of SWB in this study consisted of different numbers of items (positive affect $=$ six, negative affect $=$ six, and life satisfaction $=$ one), we divided each measure's score by the number of items before summing so that the measures were given equal presence in the overall SWB score.
} 


\section{Model 4}

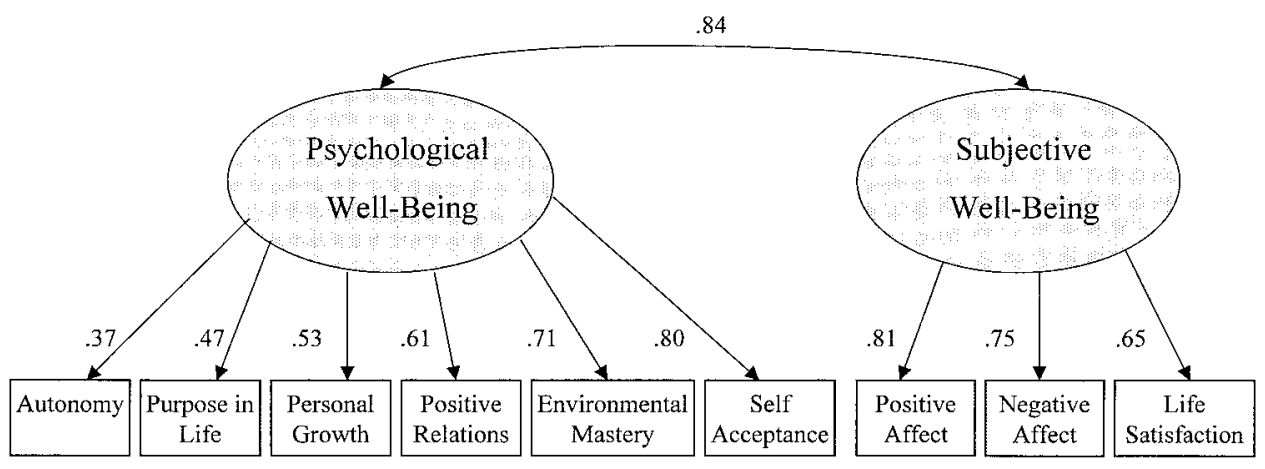

Figure 1. Standardized parameter estimates of a model of well-being with two oblique factors (Model 4).

PWB tended to be more highly educated and older than adults with the combination of low SWB and low PWB. Findings therefore strongly support the hypothesis that age and education are implicated in the unique (i.e., extreme) well-being combinations, in which we find clear age grading and educational grading of cell membership.

\section{Discriminant Analysis With the Big Five Personality Traits}

We had also hypothesized that personality contributes to the psychological differentiation of the well-being types. To investigate this hypothesis, we conducted a discriminant analysis of the four extreme combinations in the SWB $\times$ PWB crosstabulation presented in Table 6 . We tested the unique discriminatory power of the five-factor personality traits (i.e., the Big Five) after adjusting for the major sociodemographic effects, including age and educa- tion as continuous variables and gender, race, and marital status as dummies. Table 6 presents the results of the discriminant analysis with both simultaneous and stepwise solutions. The results based on the weighted sample, as currently reported, were similar to those based on the unweighted sample.

As shown in Table 6, the discriminant analysis yielded three discriminant functions that significantly explained the betweengroups variability. The stepwise solution (whose discriminant coefficients appear in parentheses) dropped out two sociodemographic variables (gender and race) and one personality variable (Agreeableness) that did not offer unique (i.e., nonredundant) contributions to the group discrimination at the .01 probability level or lower. Inspection of the distances between the centroids, which are the mean scores of the groups on the discriminant functions, indicates that the first function maximally separates between the on-diagonal types (Group 1 and 2), whereas the second function maximally separates between the off-diagonal

\section{Model 6}

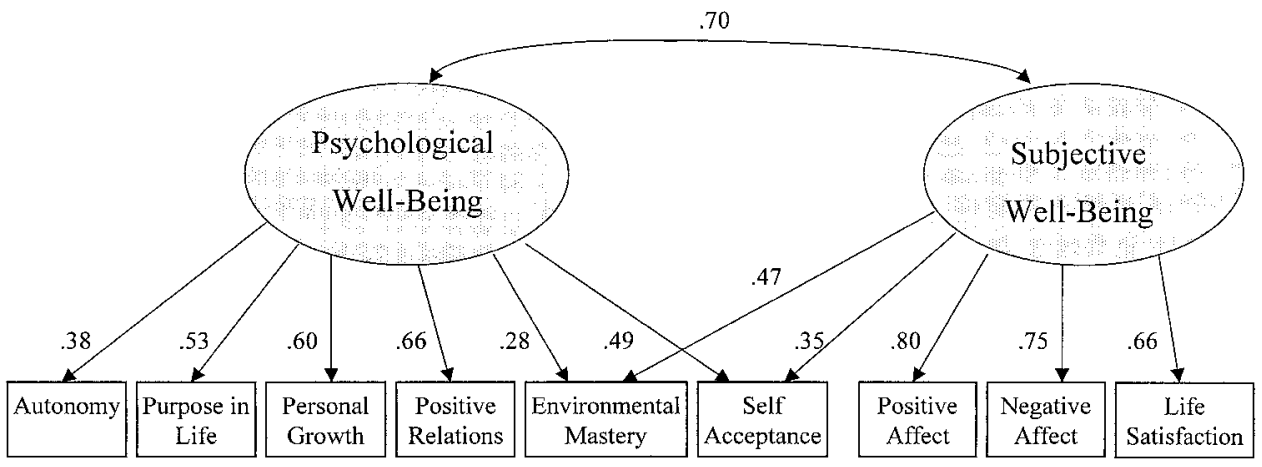

Figure 2. Standardized parameter estimates of a model of well-being with two oblique factors that have two common indicators (Model 6). 
Table 5

Multinomial Logistic Regression Coefficients of the Well-Being Combinations Onto Sociodemographic Variables (Sample Weighted)

\begin{tabular}{|c|c|c|c|c|c|c|}
\hline \multirow[b]{3}{*}{ Overall SWB ${ }^{\mathrm{a}}$} & \multicolumn{6}{|c|}{ Overall PWB } \\
\hline & \multicolumn{2}{|c|}{ Lower tertile } & \multicolumn{2}{|c|}{ Middle tertile } & \multicolumn{2}{|c|}{ Upper tertile } \\
\hline & Coefficient & Log-odd & Coefficient & Log-odd & Coefficient & Log-odd \\
\hline Lower tertile & Reference cell & & & & & \\
\hline \multicolumn{7}{|l|}{ Education } \\
\hline $0-11$ years & & & & 1.0 & & 1.0 \\
\hline 12 or GED & & & .03 & .97 & .41 & 1.5 \\
\hline $13-15$ years & & & .14 & 1.2 & $1.1 * *$ & 2.9 \\
\hline 16 years & & & $.68 * *$ & 2.0 & $1.5^{* *}$ & 4.4 \\
\hline 17 or more & & & .38 & 1.5 & $1.1^{*}$ & 3.1 \\
\hline \multicolumn{7}{|l|}{ Age } \\
\hline $25-34$ & & & & 1.0 & & 1.0 \\
\hline $35-44$ & & & -.29 & .75 & -.30 & .74 \\
\hline $45-54$ & & & .06 & 1.1 & .13 & 1.1 \\
\hline $55-64$ & & & .38 & 1.5 & .41 & 1.5 \\
\hline $65-74$ & & & -.47 & .63 & .24 & 1.3 \\
\hline \multicolumn{7}{|l|}{ Middle tertile } \\
\hline \multicolumn{7}{|l|}{ Education } \\
\hline 0-11 years & & 1.0 & & 1.0 & & 1.0 \\
\hline 12 or GED & .26 & 1.3 & $.78 * * *$ & 2.2 & .47 & 1.6 \\
\hline $13-15$ years & .03 & 1.1 & $85 * * *$ & 2.3 & $.81 * *$ & 2.2 \\
\hline 16 years & .07 & 1.1 & $1.4 * * *$ & 4.1 & $1.8^{* * *}$ & 5.8 \\
\hline 17 or more & -.20 & .81 & $1.1^{* * *}$ & 3.0 & $1.5^{* * * *}$ & 4.6 \\
\hline \multicolumn{7}{|l|}{ Age } \\
\hline 25-34 & & 1.0 & & 1.0 & & 1.0 \\
\hline $35-44$ & .29 & 1.3 & $-.42 * *$ & .66 & $-.54 * *$ & .59 \\
\hline $45-54$ & $.81 * * *$ & 2.2 & -.16 & .85 & -.11 & .89 \\
\hline $55-64$ & $1.3 * * *$ & 3.8 & .29 & 1.3 & .13 & 1.1 \\
\hline $65-74$ & $1.4 * * *$ & 4.0 & $.52 *$ & 1.7 & .28 & 1.3 \\
\hline \multicolumn{7}{|l|}{ Upper tertile } \\
\hline \multicolumn{7}{|l|}{ Education } \\
\hline $0-11$ years & & 1.0 & & 1.0 & & 1.0 \\
\hline 12 or GED & -.17 & .85 & $.73 * * *$ & 2.1 & $.58 * *$ & 1.8 \\
\hline $13-15$ years & -.39 & .68 & $.52 *$ & 1.7 & $.61 * *$ & 1.8 \\
\hline 16 years & -.45 & .64 & $1.2 * * *$ & 3.3 & $1.4^{* * * *}$ & 4.4 \\
\hline 17 or more & $-1.2^{*}$ & .31 & $.83 * *$ & 2.3 & $1.2 * * *$ & 3.5 \\
\hline \multicolumn{7}{|l|}{ Age } \\
\hline 25-34 & & 1.0 & & 1.0 & & 1.0 \\
\hline $35-44$ & .47 & 1.6 & .01 & 1.1 & -.32 & .73 \\
\hline $45-54$ & $1.3^{* * *}$ & 3.5 & .14 & 1.2 & $.40 *$ & 1.5 \\
\hline $55-64$ & $2.2 * * *$ & 8.6 & $.85 * * *$ & 2.3 & $.91 * * *$ & 2.5 \\
\hline $65-74$ & $2.6^{* * *}$ & 12.9 & $1.5 * * *$ & 4.5 & $.99 * * *$ & 2.7 \\
\hline
\end{tabular}

Note. $\quad N=3,001$ after listwise deletion of cases with missing data. Empty cells were reference categories, and the reference number for the odds ratio for the reference category is always 1.0. The analysis adjusts for the effects of gender, race, and marital status. SWB = subjective well-being; PWB = psychological well-being; GED $=$ general education development diploma.

${ }^{a}$ We divided the scales by the number of items that composed each scale (positive affect $=$ six, negative affect $=$ six, and life satisfaction $=$ one) before creating the overall SWB score.

$* p<.05 . \quad * * p<.01 . \quad * * * p<.001$ (two-tailed).

types (Group 3 and 4). With a more mixed pattern, the third function separates between the on- and the off-diagonal types.

The first function, remarkably dominant with nearly $92 \%$ of the explained variance, was highly loaded by Neuroticism and, in an opposite direction, moderately loaded by Extraversion and Conscientiousness. As can be seen in Table 6, these traits yielded the biggest contrast between the means of the two on-diagonal types. Thus, individuals who are low on both SWB and PWB (Group 1) have the highest mean of Neuroticism and the lowest means of
Extraversion and Conscientiousness, whereas those who are high on both SWB and PWB (Group 2) present the opposite.

The second function, modestly explaining $7 \%$ of the variance, was highly loaded by age and moderately loaded by education (in the opposite direction). This time, the means of these variables exhibited a differentiation between the two off-diagonal types. Thus, individuals who are high on SWB but low on PWB (Group 3 ) have the highest mean age versus the lowest means in Groups 1 and 4. Also, Group 3 has the lowest mean of education versus the 
Table 6

Discriminant Analysis of Extreme Well-Being Combinations With the Big Five Personality Traits as Discriminating Variables (Sample Weighted)

\begin{tabular}{|c|c|c|c|c|c|c|c|}
\hline \multirow[b]{3}{*}{$\begin{array}{l}\text { Variable/discriminant } \\
\text { function statistics }\end{array}$} & \multicolumn{4}{|c|}{ Means (standard deviations) of well-being combinations } & & & \\
\hline & \multirow{2}{*}{$\begin{array}{c}\text { Group 1 } \\
\text { LSWB/LPWB } \\
(n=585)\end{array}$} & \multirow{2}{*}{$\begin{array}{c}\text { Group 2 } \\
\text { HSWB/HPWB } \\
(n=561)\end{array}$} & \multirow{2}{*}{$\begin{array}{c}\text { Group 3 } \\
\text { HSWB/LPWB } \\
(n=127)\end{array}$} & \multirow{2}{*}{$\begin{array}{c}\text { Group } 4 \\
\text { LSWB/HPWB } \\
(n=91)\end{array}$} & \multicolumn{3}{|c|}{$\begin{array}{l}\text { Standardized discriminant function } \\
\text { coefficients }^{\mathrm{a}}\end{array}$} \\
\hline & & & & & Function 1 & Function 2 & Function 3 \\
\hline \multicolumn{8}{|l|}{ Covariate } \\
\hline Age & $42.54(12.12)$ & $46.86(13.45)$ & $55.18(12.96)$ & $42.82(12.58)$ & $.09(.10)$ & $.73(.75)$ & $.40(.32)$ \\
\hline Gender ${ }^{b, c}$ & $0.61(0.49)$ & $0.52(0.50)$ & $0.63(0.48)$ & $0.50(0.50)$ & -.02 & .16 & -.17 \\
\hline $\operatorname{Race}^{\mathrm{d}, \mathrm{c}}$ & $0.83(0.37)$ & $0.83(0.38)$ & $0.86(0.35)$ & $0.79(0.41)$ & -.04 & .07 & -.13 \\
\hline Education ${ }^{\mathrm{e}}$ & $1.51(1.09)$ & $1.86(1.19)$ & $1.14(0.97)$ & $1.94(1.10)$ & $.10(.09)$ & $-.40(-.41)$ & $.05(.11)$ \\
\hline Marital status $\mathrm{f}^{\mathrm{f}, \mathrm{c}}$ & $0.57(0.50)$ & $0.78(0.41)$ & $0.63(0.49)$ & $0.68(0.47)$ & $.30(.29)$ & $-.17(-.19)$ & $-.15(-.12)$ \\
\hline \multicolumn{8}{|l|}{ Personality trait } \\
\hline Neuroticism & $2.77(0.63)$ & $1.84(0.57)$ & $2.18(0.59)$ & $2.42(0.64)$ & $-.67(-.66)$ & $-.10(-.06)$ & $.65(.64)$ \\
\hline Extraversion & $2.87(0.59)$ & $3.51(0.47)$ & $3.28(0.55)$ & $3.41(0.47)$ & $.38(.43)$ & $.14(.18)$ & $.70(.57)$ \\
\hline Openness to Experience & $2.79(0.55)$ & $3.25(0.48)$ & $2.93(0.50)$ & $3.25(0.49)$ & $.09(.11)$ & $-.30(-.32)$ & $.30(.33)$ \\
\hline Agreeableness & $3.33(0.52)$ & $3.67(0.41)$ & $3.60(0.47)$ & $3.55(0.50)$ & .10 & .04 & -.34 \\
\hline Conscientiousness & $3.14(0.50)$ & $3.65(0.34)$ & $3.39(0.45)$ & $3.47(0.45)$ & $.40(.42)$ & $-.09(-.07)$ & $-.00(-.09)$ \\
\hline Significance of function & & & & & .000 & .000 & .003 \\
\hline Canonical correlation & & & & & .73 & .28 & .13 \\
\hline Explained variance $(\%)$ & & & & & 91.6 & 7.0 & 1.4 \\
\hline \multicolumn{8}{|l|}{ Centroids of: } \\
\hline Group 1 & & & & & -1.17 & -0.00 & -0.00 \\
\hline Group 2 & & & & & 1.15 & -0.01 & -0.01 \\
\hline Group 3 & & & & & 0.19 & 0.88 & 0.12 \\
\hline Group 4 & & & & & 0.16 & -0.40 & 0.46 \\
\hline
\end{tabular}

Note. $\quad N=1,364$ after listwise deletion of cases with missing data. $\mathrm{SWB}=$ subjective well-being; $\mathrm{PWB}=$ psychological well-being; $\mathrm{LSWB} / \mathrm{LPWB}=$ low SWB and low PWB; HSWB/HPWB = high SWB and high PWB; HSWB/LPWB = high SWB and low PWB; LSWB/HPWB = low SWB and high PWB.

${ }^{\text {a }}$ In parentheses are the coefficients of a stepwise solution that included only variables entered at the .01 significance level (coefficients higher than .30 are in boldface). The stepwise criterion was minimization of the overall Wilks' lambda. ${ }^{\mathrm{b}}$ Coded $0=$ male, $1=$ female. ${ }^{\mathrm{c}}$ The group mean of the dichotomous/dummy variables indicates the proportion of the higher coded category. ${ }^{\mathrm{d}}$ Coded $0=$ non-Caucasian, $1=$ Caucasian. ${ }^{\mathrm{e}}$ Coded $0=0-11$ years, $1=12$ or GED, $2=13-15$ years, $3=$ bachelor's or equivalent, $4=$ master's, $\mathrm{PhD}$, or equivalent. ${ }^{\mathrm{f}}$ Coded $0=$ currently unmarried, $1=$ married.

highest mean in Group 4. This result reflects the differential relations of SWB and PWB with age and education, as elaborated in detail above. Indicated by a weaker discriminant coefficient, Openness to Experience also appearred to affect this function, although its most pronounced differentiation was not between Groups 3 and 4 but rather between groups with high PWB (2 and 4) and groups with lower PWB (1 and 3). The third function, explaining only $1.4 \%$ of the variance, was highly loaded by Neuroticism and Extraversion and moderately loaded by age and Openness to Experience. As suggested by the ordering of the centroids, Neuroticism differentiated mainly between Group 2 (with the lowest mean on this variable) and Group 4 (with a relatively high score), whereas Extraversion differentiated mainly between Group 1 (with the lowest mean on this variable) and Group 4 (with a relatively high score). Thus, although Neuroticism and Extraversion maintained opposing directions in the ondiagonal types, they were both inclined to relatively high levels in the off-diagonal group of low SWB and high PWB.

\section{Further Analyses of the Off-Diagonal Combinations}

As the above analysis of well-being combinations was overshadowed by the powerful discrimination between the on-diagonal types, we sought to examine the off-diagonal types more closely. A stepwise discriminant analysis conducted separately for the two extreme off-diagonal types yielded one function of high significance $(p<.001)$ with a canonical correlation of .53 . Only three variables entered the discriminant function at the .01 significance level: age (with a standardized coefficient of -.64), education (.50), and Openness to Experience (.35). This result indicates that those who are low on SWB and high on PWB are most differentiated from those who are high on SWB and low on PWB by a younger age, more education, and more openness to experience. This analysis provides a parsimonious presentation of the prior result pertaining to the off-diagonal types (see Function 2 in Table 6).

To see whether the differentiation between the extreme offdiagonal cells applied to participants in all the off-diagonal cells, we conducted another discriminant analysis that contrasted all those individuals who had PWB that was higher than SWB (above the diagonal) with all those who had SWB higher than PWB (below the diagonal). The results of this analysis, presented in Table 7, are consistent with those prior. Of the sociodemographic covariates, only age and education significantly contributed to the discriminant function, whereas gender, race, and marital status made no difference between the contrasted groups even in the univariate comparisons. Of the personality traits, Openness to Experience maintained the largest significant contribution to the discriminant function, with smaller, albeit significant, contribu- 
Table 7

Discriminant Analysis of Off-Diagonal Well-Being Combinations With the Big Five Personality Traits as Discriminating Variables (Sample Weighted)

\begin{tabular}{|c|c|c|c|c|}
\hline \multirow[b]{2}{*}{$\begin{array}{l}\text { Variable/discriminant } \\
\text { function statistics }\end{array}$} & \multicolumn{2}{|c|}{$\begin{array}{l}\text { Means (standard deviations) of } \\
\text { off-diagonal combinations }\end{array}$} & \multirow[b]{2}{*}{$\begin{array}{l}\text { Univariate } F(1,1352) \\
\text { of group comparison }\end{array}$} & \multirow[b]{2}{*}{$\begin{array}{c}\text { Standardized } \\
\text { discriminant } \\
\text { function coefficient }{ }^{\mathrm{a}}\end{array}$} \\
\hline & $\begin{array}{c}\text { Group 1 } \\
\text { SWB }>\text { PWB } \\
(n=655)\end{array}$ & $\begin{array}{c}\text { Group } 2 \\
\text { PWB }>\text { SWB } \\
(n=699)\end{array}$ & & \\
\hline \multicolumn{5}{|l|}{ Covariate } \\
\hline Age & $49.70(14.04)$ & $42.66(12.50)$ & $95.10 * * *$ & $-.57(-.57)$ \\
\hline Gender ${ }^{\mathrm{b}, \mathrm{c}}$ & $0.58(0.49)$ & $0.55(0.50)$ & 0.64 & -.05 \\
\hline $\operatorname{Race}^{\mathrm{d}, \mathrm{c}}$ & $0.83(0.38)$ & $0.85(0.36)$ & 0.95 & .13 \\
\hline Education $^{\mathrm{e}}$ & $1.43(1.06)$ & $1.90(1.17)$ & $60.14 * * *$ & $.36(.39)$ \\
\hline Marital status ${ }^{\mathrm{f}, \mathrm{c}}$ & $0.73(0.45)$ & $0.68(0.47)$ & 3.45 & -.11 \\
\hline \multicolumn{5}{|l|}{ Personality trait } \\
\hline Neuroticism & $2.19(0.59)$ & $2.31(0.61)$ & $12.50 * * *$ & $.24(.26)$ \\
\hline Extraversion & $3.23(0.55)$ & $3.27(0.51)$ & 1.69 & -.18 \\
\hline Openness to Experience & $2.92(0.51)$ & $3.12(0.50)$ & $57.35 * * *$ & $.46(.39)$ \\
\hline Agreeableness & $3.52(0.47)$ & $3.54(0.45)$ & 0.56 & .06 \\
\hline Conscientiousness & $3.39(0.42)$ & $3.47(0.41)$ & $14.97 * * *$ & $.25(.25)$ \\
\hline Significance of function & & & & .000 \\
\hline Canonical correlation & & & & .35 \\
\hline \multicolumn{5}{|l|}{ Centroids of: } \\
\hline Group 1 & & & & -.39 \\
\hline Group 2 & & & & .36 \\
\hline
\end{tabular}

Note. $\quad N=1,354$ after listwise deletion of cases with missing data. $\mathrm{SWB}=$ subjective well-being; $\mathrm{PWB}=$ psychological well-being; SWB $>$ PWB = moderate SWB and low PWB, high SWB and low PWB, or high SWB and moderate PWB; PWB $>$ SWB = moderate PWB and low SWB, high PWB and low SWB, or high PWB and moderate SWB.

${ }^{\mathrm{a}}$ In parentheses are the coefficients of a stepwise solution that included only variables entered at the .01 significance level (coefficients higher than .30 are in boldface). The stepwise criterion was minimization of the overall Wilks' lambda. ${ }^{\mathrm{b}}$ Coded $0=$ male, $1=$ female. ${ }^{\mathrm{c}}$ The group mean of the dichotomous/dummy variables indicates the proportion of the higher coded category. ${ }^{\mathrm{d}}$ Coded $0=$ non-Caucasian, $1=$ Caucasian . ${ }^{\mathrm{e}}$ Coded $0=0-11$ years, $1=12$ or GED, $2=13-15$ years, $3=$ bachelor's or equivalent, $4=$ master's, PhD, or equivalent. ${ }^{\mathrm{f}}$ Coded $0=$ currently unmarried, $1=$ married. $* * * p<.001$

tions by Neuroticism and Conscientiousness. All these three traits were higher among participants with PWB greater than SWB than among those with SWB greater than PWB.

Taken as a whole, the series of discriminant analyses confirms our treatment of age and education as the two important socialstructural variables that differentiate between well-being types, particularly the off-diagonal ones. Beyond these effects, personality variables emerge as potent discriminators that play differential roles in the matrix of well-being types. Among the on-diagonal types, the coincidence of high SWB and high PWB relates primarily to low Neuroticism but also to high Extraversion and high Conscientiousness. Among the off-diagonal types, the coincidence of high PWB and low SWB relates primarily to high Openness to Experience but also, even if rather weakly, to high Neuroticism and high Conscientiousness. It is notable that Agreeableness proved redundant to all other traits in the discriminant functions.

\section{Discussion}

Two streams of research characterize the study of well-being. The first, termed SWB, started in the 1950s as part of a scientific trend seeking to quantify life quality in a climate increasingly concerned about subjectivity. The other tradition, termed PWB, started its empirical endeavors in the 1980s but stemmed from earlier theories in clinical and adult developmental psychology that underscored the individual's potential for a meaningful life and self-realization in the face of challenge. Both traditions embody humanistic values that elevate the human capacity to examine what makes life good.

Using a national sample of U.S. adults and pertinent measures from each tradition, we confirm the hypothesis that SWB and PWB represent related but distinct conceptions of well-being. The data indicate that the best fitting model is one that posits two correlated latent constructs, namely SWB and PWB, rather than two orthogonal factors (or one general factor). Thus, although these latent constructs are highly correlated, each retains its uniqueness as a distinct facet of overall well-being. Our analyses also point to possible areas of overlap between the two traditions (i.e., comparison of Model 4 and Model 6) and, in so doing, clarify the PWB indicators that are most distinctive from SWB indicators. It is not surprising that it is the strongly existential aspects of PWB (i.e., purpose in life and personal growth) that most cleanly separate from the affective and life quality assessments of subjective well-being.

Our findings extend recent work seeking to differentiate between subjective or hedonic well-being (happiness) and meaning or eudaimonic well-being (growth, purpose) (Compton et al., 
1996; McGregor \& Little, 1998; Ryan \& Deci, 2001). Our inquiry also intersects with current formulations suggesting that personal happiness is contingent on committing oneself to a meaningful and purposeful life (Baumeister, 1991; Dykman, 1998; Wong \& Fry, 1998). These perspectives bring to mind Aristotle's view of eudaimonia, which, although commonly translated to mean happiness, is more accurately characterized as the striving toward realization of one's true potential (Hudson, 1996). Several have noted that a proper understanding of the Aristotelian conception is relevant to contemporary research on well-being (Megone, 1990; Ryff, 1989a; Waterman, 1990). Our findings do not convey that purpose and meaning are pathways to happiness but only underscore that the two traditions of well-being are empirically distinct. This evidence paves the way for future inquiries to explore how PWB and SWB might influence each other through time. Framed more broadly, we see both forms of well-being usefully construed as antecendent, consequent, or even mediating variables, depending on one's guiding theory.

The cross-classification of SWB and PWB yields multiple viable types of well-being, all of which are prominently evident in the U.S. population. In this sample, $18.6 \%$ had optimal well-being, with high levels of SWB and PWB; another $12.6 \%$ of adults had moderate levels of each kind of well-being; and $19.3 \%$ reported low levels of both SWB and PWB. Additionally, a sizable portion (45.2\%) had disparate combinations of SWB and PWB. Twentythree percent of the sample had higher levels of PWB than SWB, whereas $22 \%$ of the sample had higher levels of SWB than PWB. Thus, there is a substantial portion of adults with relatively high life satisfaction and predominance of positive to negative affect but also diminished thriving and self-realization in their life pursuits. Alternatively, there are many adults who report thriving in multiple aspects of life but do not feel very satisfied or happy.

These varieties of well-being extend prior typological studies, such as McKennell's (1978) cross-classification of happiness and life satisfaction, Shmotkin's (1998) distinction between congruous and incongruous type of well-being (based on assessments of affective experience, cognitive regulation of emotion, and optimism/pessimism), and Singer et al.'s (1998) cross-classification of PWB and depression. These prior typologies followed largely separate SWB or PWB traditions. Our findings now bring these traditions together, showing that they do not simply involve overlapping distributions but rather lead to characterizations of genuinely distinct forms of what it means to be well.

When they exist at equivalent levels (i.e., on-diagonal types), SWB and PWB may complement each other by providing a sense of self-congruency. We note that the highest frequency cells in Table 5 are those with lowest and highest standing on both SWB and PWB. Thus, the two versions can serve to amplify the experience of well-being, at both the positive and the negative end of the distribution. However, SWB and PWB may also compensate for each other in the off-diagonal types. For example, higher SWB may help preserve positive feelings when PWB is not possible because of lack of opportunities, lack of resources, or compromised personal health and vitality. Alternatively, the high demands of striving to make the most of one's talents may undermine SWB but boost PWB. Such processes of compensation and complementarity constitute important avenues for future inquiry.

Although substantively focused on well-being, we situate our inquiry more broadly in the context of other efforts to benefit from the study of extreme groups (e.g., Kagan, Snidman, \& Arcus, 1998) as well as the growing interest in taxometric methods in general (Waller \& Meehl, 1998). Typologies and the methods surrounding them are flourishing realms of current science, perhaps especially among those interested in discerning types of developmental trajectories (Robins, John, \& Caspi, 1998). From this vantage point, we underscore that our formulation is not intended to be the only or the definitive typology of well-being. It emerged from an a priori interest in examining the viability of differing combinations of SWB and PWB, defined by levels within each-hence, the cross-classification scheme we chose.

Beyond testing the dimensional structure of well-being and the types resulting from it, a major aim of the study was to investigate how well-being may be contoured by sociodemographic factors and by personality traits. With regard to the former, we found, as predicted, that differing combinations of well-being are linked to age and educational standing. Adults who have low perceived quality of life (i.e., SWB) and low challenged thriving (i.e., PWB) tend to be younger adults with less education. Those who are thriving in life but show low perceived quality of life are also younger adults who have, however, much higher education than do adults who have low perceived quality of life and low challenged thriving. Alternatively, adults with high perceived life quality but low challenged thriving tend to have less education and are more likely to be midlife and older adults. Optimal well-being is clearly tied to education and age: Midlife and older adults who had attained higher levels of education were most likely to be thriving in life and have high perceived quality of life.

Also as predicted, our findings link combinations of well-being to personality dispositions. In a discriminant analytic strategy, we first looked for personality differentiations among the four SWB $\times$ PWB combinations that represented the variants of on- and offdiagonal types. Results showed that of the Big Five dimensions, Neuroticism discriminated most strongly between the on-diagonal types. Such a finding is not surprising, as it converges with extensive prior research (Costa \& McCrae, 1980; Diener \& Lucas, 1999; Diener et al., 1999; Emmons \& Diener, 1985; Headey \& Wearing, 1989; Schmutte \& Ryff, 1997; Watson \& Clark, 1992), including DeNeve and Cooper's (1998) meta-analysis, which found that Neuroticism is the strongest predictor of life satisfaction, happiness, and negative affect. We also found that high Extraversion and high Conscientiousness differentiated those who were high on both SWB and PWB from those who had low profiles on both. These findings also coincide with prior evidence linking Extraversion to positive affect as well as to numerous dimensions of PWB (see preceding citations). However, the considerable attention paid to Extraversion, particularly as the counterpart of Neuroticism, has perhaps led researchers to overlook the role of Conscientiousness as a strong predictor of SWB as well as PWB (see DeNeve \& Cooper, 1998; Schmutte \& Ryff, 1997). In short, our results point to the prominence of these three personality characteristics in our understanding of combinations of SWB and PWB, either in low or in high levels.

Regarding the off-diagonal types of well-being, which represented about $45 \%$ of the sample, discriminant analyses support the hypothesis that Openness to Experience differentiates between those with discordant combinations of SWB and PWB. This finding represents a novel contribution to research on personality and well-being and reflects the growing interest in the consequences of 
openness to experience (McCrae, 1996). We found that those with high levels of psychological thriving (i.e., PWB) but low levels of happiness (i.e., SWB) were distinguished from their opposite counterpart (high SWB/low PWB) by their high levels of Openness to Experience. Further, the high thriving/low happiness combination was also linked, although less strongly, to high Neuroticism and high Conscientiousness. As suggested by McCrae and Costa (1991), high Openness may enlarge the potential and capabilities of individuals for self-fulfillment at the same time that it may invoke costs regarding negative feelings and evaluations of life. Alternatively, low Openness may preserve a restricted, possibly safer range of individuals' potentialities, a constraint that may facilitate greater life contentment. Contrary to our speculation, we found no evidence that Agreeableness differentiates those with low PWB but high SWB. Overall, the emerging picture of personality concomitants of well-being types adds to the viability of our typological approach by pointing to consistencies with prior research but also by extending them in new directions that call, of course, for replication. Future research should also investigate whether individuals with the off-diagonal types of well-being are struggling with or have reconciled tensions between the search for meaning and the desire for manageability in life (see McGregor \& Little, 1998).

Our study is limited by the static, single-point-in-time assessment of all aspects of well-being. Applied to the cross-sectional age comparisons, it is impossible to ascertain whether observed age differences reflect the maturational and accommodative life course processes we have described or, alternatively, indicate nonchanging differences between age cohorts. Longitudinal and sequential designs are needed to clarify which of these interpretations is more compelling. Beyond such life-course developmental questions, however, are numerous issues pertaining to the dynamics of well-being, both in terms of how SWB and PWB might influence each other through time and in terms of how both may be influenced by environmental changes and life events (Kling, Ryff, \& Essex, 1997; Kling, Seltzer, \& Ryff, 1997; Smider et al., 1996; Stones, Hadjistavropoulos, Tuuko, \& Kozma, 1995). There may also be more gradual shifts in well-being in response to accumulated advantages and adversities experienced during the life-span (Keyes \& Ryff, 1998; Ryff et al., 1998). And, as our opening literature review reveals, numerous adaptation processes (social comparisons, coping strategies, goal orientations, etc.) are also pertinent to tracking changing configurations of SWB and PWB.

It must also be acknowledged that both traditions of well-being brought together in this inquiry may reflect largely Western and, possibly, middle- and upper class characterizations of what it means to live a full and satisfying life. There are other ways of construing the ultimate criterial goods in life (see, e.g., Becker, 1992; Coan, 1977; Keyes, 1998). In this sense, the present encounter of two traditions heralds possibly new encounters with diverse cultural and ethnic varieties of well-being. Eastern perspectives may, for example, overshadow imagery of the happy, upbeat, striving, potential-reaching self with conceptions that are about connection to others, meeting obligations therein, and achieving fulfillment through carefully managed social ties.

Finally, although our primary aims have been to clarify the varieties of well-being that are anchored in the constraints and opportunities of the life course, educational hierarchy, and personality, we do not wish to overlook the interventive and public policy implications of this inquiry. A first point is that the absence of perceived quality of life and challenged thriving (i.e., the low-low cell of our typology), which involved $19 \%$ of the sample, constitutes an important societal challenge in its own right (Keyes, in press; Keyes \& Lopez, 2002). The absence of well-being is, to our minds, a neglected malaise among prevalent formulations of mental health that emphasize exclusively negative criteria (e.g., depression, anxiety). Secondly, even though we have suggested that well-being is contoured, in part, by sociodemographic factors and personality characteristics, it should not be seen as immutably the product of large forces beyond the control of the individual or the interventive purview of the practitioner. Among exciting new directions for promoting healthy living, particularly among those who most need it (i.e., individuals who suffer from recurrent depression), is well-being therapy (Fava, 1999; Fava et al., 1998). Remission profiles of those receiving such therapy offer hope that well-being can also be contoured by proactive interventions designed to help individuals increase and enrich their experience of the positive, the many varieties of which were the starting point for this inquiry.

\section{References}

Adler, N. E., McEwen, B. S., \& Marmot, M. (Eds.). (1999). Socioeconomic status and health in industrialized countries. Annals of the New York Academy of Sciences, 896, 96-115.

Allport, G. W. (1961). Pattern and growth in personality. New York: Holt, Rinehart, \& Winston.

Andrews, F. M., \& Robinson, J. P. (1991). Measures of subjective wellbeing. In J. P. Robinson, P. R. Shaver, \& L. S. Wrightsman (Eds.), Measures of personality and social psychological attitudes (Vol. 1, pp. 61-114). San Diego, CA: Academic Press.

Andrews, F. M., \& Withey, S. B. (1976). Social indicators of well-being: Americans' perceptions of life quality. New York: Plenum.

Baumeister, R. F. (1991). Meanings of life. New York: Guilford Press.

Becker, L. C. (1992). Good lives: Prolegomena. Social Philosophy and Policy, 9, 15-37.

Bradburn, N. M. (1969). The structure of psychological well-being. Chicago: Aldine.

Cacioppo, J. T., Gardner, W. L., \& Berntson, G. G. (1999). The affect system has parallel and integrative processing components: Form follows function. Journal of Personality and Social Psychology, 76, 839855.

Campbell, A., Converse, P. E., \& Rodgers, W. L. (1976). The quality of American life: Perceptions, evaluations, and satisfactions. New York: Russell Sage Foundation.

Cantril, H. (1965). The pattern of human concerns. New Brunswick, NJ: Rutgers University Press.

Carr, D. (1997). The fulfillment of career dreams at midlife: Does it matter for women's mental health? Journal of Health and Social Behavior, 38, 331-344.

Charles, S. T., Reynolds, C. A., \& Gatz, M. (2001). Age-related differences and change in positive and negative affect over 23 years. Journal of Personality and Social Psychology, 80, 136-151.

Clarke, P. J., Marshall, V. W., Ryff, C. D., \& Rosenthal, C. J. (2000). Well-being in Canadian seniors: Findings from the Canadian Study of Health and Aging. Canadian Journal on Aging, 19, 139-159.

Coan, R. W. (1977). Hero, artist, sage, or saint? A survey of what is variously called mental health, normality, maturity, self-actualization, and fulfillment. New York: Columbia University Press.

Compton, W. C., Smith, M. L., Cornish, K. A., \& Qualls, D. L. (1996). Factor structure of mental health measures. Journal of Personality and Social Psychology, 76, 406-413. 
Costa, P. T., \& McCrae, R. R. (1980). Influence of extroversion and neuroticism on subjective well-being: Happy and unhappy people. Journal of Personality and Social Psychology, 38, 668-678.

DeNeve, K. M., \& Cooper, H. (1998). The happy personality: A metaanalysis of 137 personality traits and well-being. Psychological Bulletin, 124, 197-229.

Diener, E., \& Lucas, R. E. (1999). Personality and subjective well-being. In D. Kahneman, E. Diener, \& N. Schwarz (Eds.), Well-being: The foundations of hedonic psychology (pp. 213-229). New York: Russell Sage Foundation.

Diener, E., Sandvik, E., \& Pavot, W. (1991). Happiness is the frequency, not the intensity, of positive versus negative affect. In F. Strack, M. Argyle, \& N. Schwarz (Eds.), Subjective well-being: An interdisciplinary perspective (pp. 119-139). Oxford, England: Pergamon.

Diener, E., Smith, H., \& Fujita, F. (1995). The personality structure of affect. Journal of Personality and Social Psychology, 69, 130-141.

Diener, E., \& Suh, M. E. (1997). Subjective well-being and age: An international analysis. Annual Review of Gerontology and Geriatrics, $17,304-324$.

Diener, E., Suh, E. M., Lucas, R. E., \& Smith, H. L. (1999). Subjective well-being: Three decades of progress. Psychological Bulletin, 125, 276-302.

Dykman, B. M. (1998). Integrating cognitive and motivational factors in depression: Initial tests of a goal-orientation approach. Journal of Personality and Social Psychology, 74, 139-158.

Emmons, R. A. (1986). Personal strivings: An approach to personality and subjective well-being. Journal of Personality and Social Psychology, 51, $1058-1068$

Emmons, R. A. (1996). Striving and feeling: Personal goals and subjective well-being. In P. M. Golwitzer \& J. A. Bargh (Eds.), The psychology of action: Linking cognition and motivation to behavior (pp. 313-337). New York: Guilford Press.

Emmons, R. A., \& Diener, E. (1985). Personality correlates of subjective well-being. Personality and Social Psychology Bulletin, 11, 89-97.

Erikson, E. (1959). Identity and the life cycle. Psychological Issues, 1, $18-164$.

Fava, G. A. (1999). Well-being therapy: Conceptual and technical issues. Psychotherapy and Psychosomatics, 68, 171-179.

Fava, G. A., Rafanelli, C., Grandi, S., Conti, S., \& Belluardo, P. (1998). Prevention of recurrent depression with cognitive behavioral therapy. Archives of General Psychiatry, 56, 479-480.

Feist, G. J, Bodner, T. E., Jacobs, J. F., Miles, M., \& Tan, V. (1995). Integrating top-down and bottom-up structural models of subjective well-being: A longitudinal investigation. Journal of Personality and Social Psychology, 68, 138-150.

Green, D. P., Goldman, S. L., \& Salovey, P. (1993). Measurement error masks bipolarity in affect ratings. Journal of Personality and Social Psychology, 64, 1029-1041.

Gurin, G., Veroff, J., \& Feld, S. (1960). Americans view their mental health. New York: Basic Books.

Headey, B., \& Wearing, A. (1989). Personality, life events, and subjective well-being: Toward a dynamic equilibrium model. Journal of Personality and Social Psychology, 57, 731-739.

Heidrich, S. M., \& Ryff, C. D. (1993). The role of social comparisons processes in the psychological adaptation of elderly adults. Journal of Gerontology, 48, 127-136.

Hudson, D. W. (1996). Happiness and the limits of satisfaction. Lanham, MD: Rowman \& Littlefield.

Jahoda, M. (1958). Current concepts of positive mental health. New York: Basic Books.

John, O. P. (1990). The "Big Five" factor taxonomy: Dimensions of personality in the natural language and in questionnaires. In L. A. Pervin (Ed.), Handbook of personality theory and research (pp. 66-100). New York: Guilford Press.
Jöreskog, K., \& Sörbom, D. (1996). LISREL 8: User's reference guide. Chicago: Scientific Software International.

Jung, C. G. (1933). Modern man in search of a soul. New York: Harcourt, Brace, \& World.

Kagan, J., Snidman, N., \& Arcus, D. (1998). The value of extreme groups. In R. C. Cairns, L. R. Bergman, \& J. Kagan (Eds.), Methods and models for studying the individual (pp. 65-79). Thousand Oaks, CA: Sage.

Kahneman, D., Diener, E., \& Schwarz, N. (Eds.). (1999). Well-being: The foundations of hedonic psychology. New York: Russell Sage Foundation.

Keyes, C. L. M. (1998). Social well-being. Social Psychology Quarterly, 61, 121-140.

Keyes, C. L. M. (2000). Subjective change and its consequences for emotional well-being. Motivation and Emotion, 24(2), 67-84.

Keyes, C. L. M. (in press). The mental health continuum: From languishing to flourishing in life. Journal of Health and Social Behavior.

Keyes, C. L. M., \& Lopez, S. J. (2002). Toward a science of mental health: Positive directions in diagnosis and interventions. In C. R. Snyder \& S. J. Lopez (Eds.), Handbook of positive psychology (pp. 45-59). New York: Oxford University Press.

Keyes, C. L. M., \& Ryff, C. D. (1998). Generativity in adult lives: Social structural contours and quality of life consequences. In D. McAdams \& E. de St. Aubin (Eds.), Generativity and adult development: Perspectives on caring for and contributing to the next generation (pp. 227263). Washington, DC: American Psychological Association.

King, L. A., \& Napa, C. K. (1998). What makes a life good? Journal of Personality and Social Psychology, 75, 156-165.

Kling, K. C., Ryff, C. D., \& Essex, M. J. (1997). Adaptive changes in self-concept during a life transition. Personality and Social Psychology Bulletin, 23, 989-998.

Kling, K. C., Seltzer, M. M., \& Ryff, C. D. (1997). Distinctive late life challenges: Implications for coping and well-being. Psychology and Aging, 12, 288-295.

Lachman, M. E., \& Weaver, S. L. (1997). The Midlife Development Inventory (MIDI) personality scales: Scale construction and scoring (Technical Report). Waltham, MA: Brandeis University.

Land, K. C. (1975). Social indicators models: An overview. In K. C. Land \& S. Spilerman (Eds.), Social indicator models (pp. 5-36). New York: Russell Sage Foundation.

Lawton, M. P. (1975). The Philadelphia Geriatric Center Morale Scale: A revision. Journal of Gerontology, 30, 85-89.

Lazarus, R. S. (1991). Emotion and adaptation. New York: Oxford University Press.

Li, L. W., Seltzer, M. M., \& Greenberg, J. S. (1999). Change in depressive symptoms among daughter caregivers: An 18-month longitudinal study. Psychology and Aging, 14, 206-219.

Liang, J. (1984). Dimensions of the Life Satisfaction Index A: A structural formulation. Journal of Gerontology, 39, 613-622.

Lucas, R. E., Diener, E., \& Suh, E. (1996). Discriminant validity of well-being measures. Journal of Personality and Social Psychology, 71, 616-628.

Lykken, D., \& Tellegen, A. (1996). Happiness is a stochastic phenomenon. Psychological Science, 7, 186-189.

Marks, N. F., \& Lambert, J. D. (1998). Marital status continuity and change among young and midlife adults: Longitudinal effects on psychological well-being. Journal of Family Issues, 19, 652-686.

Marmot, M., Ryff, C. D., Bumpass, L. L., Shipley, M., \& Marks, N. F. (1997). Social inequalities in health: Converging evidence and next questions. Social Science and Medicine, 44, 901-910.

Maslow, A. (1968). Toward a psychology of being (2nd ed.). New York: Van Nostrand.

McCrae, R. R. (1996). Social consequences of experiential openness. Psychological Bulletin, 120, 323-337.

McCrae, R. R., \& Costa, P. T. Jr. (1991). Adding Liebe und Arbeit: The full 
five-factor model and well-being. Personality and Social Psychology Bulletin, 17, 227-232.

McCrae, R. R., \& Costa, P. T. Jr. (1994). The stability of personality: Observations and evaluations. Current Directions in Psychological Science, 3, 173-175.

McGregor, I., \& Little, B. R. (1998). Personal projects, happiness, and meaning: On doing well and being yourself. Journal of Personality and Social Psychology, 74, 494-512.

McKennell, A. C. (1978). Cognition and affect in perceptions of wellbeing. Social Indicators Research, 5, 389-426.

McKinley, N. M. (1999). Women and objectified body consciousness: Mothers' and daughters' body experience in cultural, development, and familial context. Developmental Psychology, 35, 760-769.

Megone, C. (1990). The quality of life: Starting from Aristotle. In S. Baldwin, C. Godfrey, \& C. Propper (Eds.), Quality of life: Perspectives and policies (pp. 28-54). London: Routledge.

Michalos, A. C. (1985). Multiple discrepancies theory (MDT). Social Indicators Research, 16, 347-414.

Mroczek, D. K., \& Kolarz, C. M. (1998). The effect of age on positive and negative affect: A developmental perspective on happiness. Journal of Personality and Social Psychology, 75, 1333-1349.

Neugarten, B. L. (1968). The awareness of middle age. In B. L. Neugarten (Ed.), Middle age and aging (pp. 93-98). Chicago: University of Chicago Press.

Neugarten, B. L. (1973). Personality change in late life: A developmental perspective. In C. Eisdorfer \& M. P. Lawton (Eds.), The psychology of adult development and aging (pp. 311-335). Washington, DC: American Psychological Association.

Neugarten, B. L., Havighurst, R. J., \& Tobin, S. S. (1961). The measurement of life satisfaction. Journal of Gerontology, 16, 134-143.

Okun, M. A. (1995). Subjective well-being. In G. L. Maddox (Ed.), The encyclopedia of aging (2nd ed., pp. 909-912). New York: Springer.

Omodei, M. M., \& Wearing, A. J. (1990). Need satisfaction and involvement in personal projects: Toward an integrative model of subjective well-being. Journal of Personality and Social Psychology, 59, 762-769.

Prenda, K. M., \& Lachman, M. E. (2001). Planning for the future: A life management strategy for increasing control and life satisfaction in adulthood. Psychology and Aging, 16, 206-216.

Raphael, D., Renwick, R., Brown, I., \& Rootman, I. (1996). Quality of life indicators and health: Current status and emerging conceptions. Social Indicators Research, 39, 65-88.

Riley, M. W., Kahn, R. L., \& Foner, A. (1994). Age and structural lag. New York: Wiley,

Robins, R. W., John, O. P., \& Caspi, A. (1998). The typological approach to studying personality. In R. B. Cairns, L. R. Bergman, \& J. Kagan (Eds.), Methods and models for studying the individual: Essays in honor of Marian Radke-Yarrow (pp. 135-160). Thousand Oaks, CA: Sage.

Rogers, C. R. (1961). On becoming a person. Boston: Houghton Mifflin.

Russell, J. A., \& Carroll, J. M. (1999). On the bipolarity of positive and negative affect. Psychological Bulletin, 125, 3-30.

Ryan, R. M., \& Deci, E. L. (2001). On happiness and human potentials: A review of research on hedonic and eudaimonic well-being. Annual Review of Psychology, 52, 141-166.

Ryff, C. D. (1985). Adult personality development and the motivation for personal growth. In D. Kleiber \& M. Maher (Eds.), Advances in motivation and achievement: Motivation and adulthood (Vol. 4, pp. 55-92). Greenwich, CT: JAI Press.

Ryff, C. D. (1989a). Happiness is everything, or is it? Explorations on the meaning of psychological well-being. Journal of Personality and Social Psychology, 57, 1069-1081.

Ryff, C. D. (1989b). In the eye of the beholder: Views of psychological well-being among middle-aged and older adults. Psychology and Aging, 4, 195-210.

Ryff, C. D., \& Keyes, C. L. M. (1995). The structure of psychological well-being revisited. Journal of Personality and Social Psychology, 69, 719-727.

Ryff, C. D., \& Marshall, V. W. (Eds.). (1999). The self and society in aging processes. New York: Springer.

Ryff, C. D., Schmutte, P. S., \& Lee, Y. H. (1996). How children turn out: Implications for parental self-evaluation. In C. D. Ryff \& M. M. Seltzer (Eds.), The parental experience in midlife (pp. 383-422). Chicago: University of Chicago Press.

Ryff, C. D., \& Singer, B. (1996). Psychological well-being: Meaning, measurement, and implications for psychotherapy research. Psychotherapy and Psychosomatics, 65, 14-23.

Ryff, C. D., Singer, B., Love, G. D., \& Essex, M. J. (1998). Resilience in adulthood and later life: Defining features and dynamic processes. In J. Lomranz (Ed.), Handbook of aging and mental health: An integrative approach (pp. 69-96). New York: Plenum.

Schmutte, P. S., \& Ryff, C. D. (1997). Personality and well-being: Reexamining methods and meanings. Journal of Personality and Social Psychology, 73, 549-559.

Schwarz, N., \& Clore, G. L. (1983). Mood, misattribution, and judgments of well-being: Informative and directive functions of affective states. Journal of Personality and Social Psychology, 45, 513-523.

Schwarz, N., \& Strack, F. (1999). Reports of subjective well-being: Judgmental processes and their methodological implications. In D. Kahneman, E. Diener, \& N. Schwarz (Eds.), Well-being: The foundations of hedonic psychology (pp. 61-84). New York: Russell Sage Foundation.

Sheldon, K. M., \& Elliot, A. J. (1999). Goal striving, need satisfaction, and longitudinal well-being: The self-concordance model. Journal of Personality and Social Psychology, 76, 482-497.

Shmotkin, D. (1990). Subjective well-being as a function of age and gender: A multivariate look for differentiated trends. Social Indicators Research, 23, 201-230.

Shmotkin, D. (1991). The role of time orientation in life satisfaction across the life-span. Journal of Gerontology: Psychological Sciences, 46, $243-$ 250.

Shmotkin, D. (1998). Declarative and differential aspects of subjective well-being and implications for mental health in later life. In J. Lomranz (Ed.), Handbook of aging and mental health: An integrative approach (pp. 15-43). New York: Plenum.

Shmotkin, D., \& Hadari, G. (1996). An outlook on subjective well-being in older Israeli adults: A unified formulation. International Journal of Aging and Human Development, 42, 271-289.

Shmotkin, D., \& Lomranz, J. (1998). Subjective well-being among Holocaust survivors: An examination of overlooked differentiations. Journal of Personality and Social Psychology, 75, 141-155.

Singer, B., Ryff, C. D., Carr, D., \& Magee, W. J. (1998). Life histories and mental health: A person-centered strategy. In A. Raftery (Ed.), Sociological methodology. Washington, DC: American Sociological Association.

Smider, N. A., Essex, M. J., \& Ryff, C. D. (1996). Adaptation to community relocation: The interactive influence of psychological resources and contextual factors. Psychology and Aging, 11, 362-371.

Stones, M. J., Hadjistavropoulos, T., Tuuko, H., \& Kozma, A. (1995). Happiness has traitlike and statelike properties: A reply to Veenhoven. Social Indicators Research, 36, 129-144.

Strack, F., Schwarz, N., \& Gschneidinger, E. (1985). Happiness and reminiscing: The role of time perspective, affect, and mode of thinking. Journal of Personality and Social Psychology, 49, 1460-1469.

Suh, E., Diener, E., Oishi, S., \& Triandis, H. C. (1998). The shifting basis of life satisfaction judgments across cultures: Emotions versus norms. Journal of Personality and Social Psychology, 74, 482-493.

Tversky, A., \& Griffin, D. (1991). Endowment and contrast in judgments of well-being. In F. Strack, M. Argyle, \& N. Schwarz (Eds.), Subjective well-being: An interdisciplinary perspective (pp. 101-118). Oxford, England: Pergamon. 
Veenhoven, R. (1991). Is happiness relative? Social Indicators Research, 24, 1-34.

Waller, N. G., \& Meehl, P. E. (1998). Multivariate taxometric procedures: Distinguishing types from continua. Thousand Oaks, CA: Sage.

Waterman, A. S. (1990). The relevance of Aristotle's conception of eudaimonia for the psychological study of happiness. Theoretical and Philosophical Psychology, 10, 39-44.

Waterman, A. S. (1993). Two conceptions of happiness: Contrasts of personal expressiveness (eudaimonia) and hedonic enjoyment. Journal of Personality and Social Psychology, 64, 678-691.

Watson, D., \& Clark, L. A. (1992). On traits and temperament: General and specific factors of emotional experience and their relation to the fivefactor model. Journal of Personality, 60, 441-476.

Witter, R. A., Okun, M. A., Stock, W. A., \& Haring, M. J. (1984). Education and subjective well-being: A meta-analysis. Education Evaluation and Policy Analysis, 6, 165-173.

Wong, P. T. P., \& Fry, P. S. (Eds.). (1998). The human quest for meaning. Mahwah, NJ: Erlbaum.

Received March 14, 2001

Revision received December 27, 2001

Accepted January 3, 2002

\section{American Psychological Association SUBSCRIPTION ClaIMS INFORMATION}

Today's Date:

We provide this form to assist members, institutions, and nonmember individuals with any subscription problems. With the appropriate information we can begin a resolution. If you use the services of an agent, please do NOT duplicate claims through them and directly to us. PLEASE PRINT CLEARLY AND IN INK IF POSSIBLE.

\begin{tabular}{llll}
\hline PRINT FULL NAME OR KEY NAME OF INSTITUTION & & \\
\hline ADDRESS & & & \\
\hline CITY & & & \\
\hline
\end{tabular}

YOUR NAME AND PHONE NUMBER

TITLE

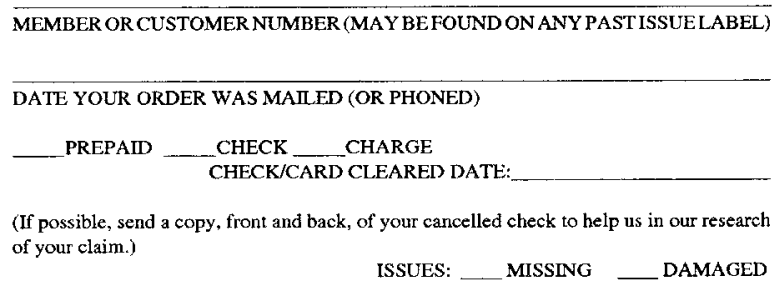

VOLUME OR YEAR

Thank you. Once a claim is received and resolved, delivery of replacement issues routinely takes 4-6 weeks.

(TO BE FILLED OUT BY APA STAFF)

DATE RECEIVED:

ACTION TAKEN:

STAFF NAME:
DATE OF ACTION:

INV. NO. \& DATE:

LABEL NO. \& DATE:

Send this form to APA Subscription Claims, 750 First Street, NE, Washington, DC 20002-4242

PLEASE DO NOT REMOVE. A PHOTOCOPY MAY BE USED. 